\title{
Thermogravimetric Analysis of Modified Montmorillonite Clay for Mycotoxin Decontamination in Cereal Grains
}

\author{
Bunmi K. Olopade $\mathbb{D}^{1,}{ }^{1,2}$ Obinna C. Nwinyi ${ }^{1},{ }^{1,2}$ Joseph A. Adekoya, ${ }^{3}$ Isiaka A. Lawal, ${ }^{4}$ \\ Olushola A. Abiodun, ${ }^{5}$ Solomon U. Oranusi $\mathbb{D}^{1}{ }^{1}$ and Patrick B. Njobeh ${ }^{2}$ \\ ${ }^{1}$ Department of Biological Sciences, College of Science and Technology, Covenant University, Km 10, Idiroko Road, Ota, \\ Ogun, Nigeria \\ ${ }^{2}$ Department of Biotechnology and Food Technology, University of Johannesburg, Doornfontein Campus, Johannesburg, \\ Gauteng 2028, South Africa \\ ${ }^{3}$ Department of Chemistry, College of Science and Technology, Covenant University, Km 10, Idiroko Road, Ota, Ogun, Nigeria \\ ${ }^{4}$ Vaal University of Technology, Vanderbijlpark Campus, Boulevard, Vanderbijlpark 1900, South Africa \\ ${ }^{5}$ Department of Biological Oceanography, Nigerian Institute for Oceanography and Marine Research, Victoria Island, \\ Lagos 101241, Nigeria \\ Correspondence should be addressed to Bunmi K. Olopade; bunmi.olopade@covenantuniversity.edu.ng
}

Received 19 August 2020; Revised 24 October 2020; Accepted 15 November 2020; Published 29 November 2020

Academic Editor: Cezary Sławiński

Copyright (c) 2020 Bunmi K. Olopade et al. This is an open access article distributed under the Creative Commons Attribution License, which permits unrestricted use, distribution, and reproduction in any medium, provided the original work is properly cited.

\begin{abstract}
Thermogravimetric analysis (TGA) was carried out to study the stability of nanoformulations used for the decontamination of mycotoxins. The TGA patterns of the nanoformulations from montmorillonite clay and Cymbopogon citratus (lemongrass) extracts were assessed with temperature ranging from ambient $\left(20^{\circ} \mathrm{C}\right)$ to $1000^{\circ} \mathrm{C}$. The various nanoformulations studied included unmodified montmorillonite clay (Mont), montmorillonite washed with sodium chloride (Mont-Na), montmorillonite mixed with lemongrass essential oil (Mont-LGEO), and montmorillonite mixed with an equal quantity of lemongrass powder (MontLGP). There was no significant difference in the median of the various nanoformulations within 4 weeks at $p<0.05$ using the Kruskal-Wallis nonparametric test. For the TGA, the first degradation for montmorillonite clay and the nanoformulations occurred at a temperature between 80 and $101^{\circ} \mathrm{C}$ and was attributed to the loss of lattice water outside the coordination sphere with a range of 3.5-6.5\% weight loss. The second degradation occurred within the temperature of 338 to $344^{\circ} \mathrm{C}$, and the third, at a temperature between 640 and $668^{\circ} \mathrm{C}$ for Mont and the formulations of Mont-Na, Mont-LGEO, and Mont-LGP. There were strong similarities in the degradation patterns of Mont and Mont-Na with the minimum difference being the relatively higher weight loss of the sodium-exchanged cation for Mont-Na at the third degradation step. Hence, the order of stability from the most resistant to the least resistant to degradation is as follows: Mont-LGEO $\geq$ Mont-Na $\geq$ Mont $\geq$ Mont-LGP.
\end{abstract}

\section{Introduction}

Montmorillonite clay has been used for several applications, including the adsorption of mycotoxins in feeds [1]. The cytotoxic properties of montmorillonite clay are insignificant, making it readily efficient for use as excipients in oral and topical drugs [2]. The space between the layers of montmorillonite makes up about $90 \%$ of its entire surface. Hence, it enhances the ability of clay to absorb molecules of water and other polar molecules $[3,4]$.
The main mycotoxins of public concern that often occur in cereal grains such as maize are aflatoxins, deoxynivalenol, fumonisins, ochratoxins, and zearalenone $[5,6]$. High incidences of mycotoxins, such as fumonisins and zearalenone in maize, have also been reported $[7,8]$.

Different types of clay, including bentonite, have been employed for the decontamination of mycotoxins in food and feed [9], thus serving as mycotoxin binders. Other commercial mycotoxin binders employed in feeds include 
Mycosorb, Formycin, and Anzymit, amongst others [10]. Cymbopogon citratus (lemongrass) powder and extracts are equally effective in decontaminating mycotoxins in crops [11-13]. Furthermore, a mixture of montmorillonite clay and lemongrass has been applied for the same purpose in cereal grains. Modified montmorillonite clay has proven efficient in decontaminating T-2 toxin in maize and zearalenone in millet $[14,15]$. The use of clay for decontamination of mycotoxins is an adsorption approach, which involves chemical and physical forces that help decrease the formation of toxins and lessen their health effects thereof in animals [16]. In a bid to validate the use of nanoformulations from clay for mycotoxin decontamination, it is essential to ensure that such nanoformulations remain viable and not depleted. This study, therefore, aimed to investigate the stability of various nanoformulations made from montmorillonite clay combined with powder and extracts of lemongrass.

\section{Materials and Methods}

2.1. Sample Preparation. Montmorillonite K10 powder (CAS number 1318-93-0) purchased from Sigma-Aldrich, Germany, was used, while the leaves of Cymbopogon citratus utilised in the study were identified at the Botany Unit of the Department of Biological Sciences, Covenant University, Nigeria. Lemongrass (Cymbopogon citratus) leaves were cleaned using distilled water and air-dried at $25^{\circ} \mathrm{C}$ for three weeks. After drying, the leaves were pulverised using an electric blender (IKA M20, Wilmington, NC, USA). Soxhlet extraction method, as described by Ojewumi et al. [17], was used to obtain the extracts from lemongrass. For extraction, $250 \mathrm{~mL}$ of hexane was added to $25 \mathrm{~g}$ of the lemongrass powder and extracted using a rotary evaporator (IKARV10, Staufen, Germany). The concentrated crude essential oil was used to prepare Mont-LGEO according to the modified method of Noudem et al. [18]. The nanoformulations used for the decontamination of $\mathrm{AFG}_{1}$ in millet were prepared as described by Olopade et al. [14]. The decontamination process for these two toxins was studied by mixing the nanoformulations with the cereal grains and storing over four weeks. The same approach was applied for the decontamination of $\mathrm{AFG}_{1}$ in millet in this study. The preparation of Mont-LGEO involved the homogenisation of montmorillonite clay with sodium chloride solution $\left(1 \mathrm{~mol} \mathrm{~L}^{-1}\right)(1: 20, \mathrm{w} / \mathrm{v})$ at $25^{\circ} \mathrm{C}$ followed by dialysation of the mixture in deionized water to get rid of chloride ions. The mixture was centrifuged at $50 \mathrm{rpm}$ for $5 \mathrm{~min}$, and the supernatant decanted, while the resulting dialysed mixture was dried at $40^{\circ} \mathrm{C}$ in an oven to allow water evaporation from the clay. Montmorillonite was mixed with $50 \mathrm{~mL}$ of essential oil solution $(\mathrm{v} / \mathrm{v})$ prepared using acetone. The essential oil solution was prepared by dissolving $5 \mathrm{~mL}$ of the crude essential oil in $45 \mathrm{~mL}$ of acetone. The mixture was homogenised at $25^{\circ} \mathrm{C}$ in an overhead shaker at $50 \mathrm{rpm}$ and then secured in a hot water bath set at $60^{\circ} \mathrm{C}$ for $90 \mathrm{~min}$ to dry out acetone. The mixture (Mont-LGEO) was dried in an oven overnight at $30^{\circ} \mathrm{C}$ and then stored in tightly sealed coloured vials. For the Mont-Na mixture, montmorillonite clay was modified by the homogenisation of montmorillonite clay with $\mathrm{NaCl}$ solution $\left(1 \mathrm{~mol} \mathrm{~L}^{-1}\right)(1: 20$, w/v). The last formulation, Mont-LGP, was prepared by mixing montmorillonite with an equal quantity of lemongrass powder (Mont-LGP).

\subsection{Thermogravimetric Analysis of Modified Clay.} Thermogravimetric analysis of the various types of modified clay was carried out with the aid of STA7200RV Thermal Analysis system. Each powder sample was placed in an alumina crucible (6 $\mathrm{mm}$ diameter). A constant heating rate of $5^{\circ} \mathrm{C} / \mathrm{min}$ was applied from 20 to $1000^{\circ} \mathrm{C}$ under nitrogen atmosphere with a flow rate of $50 \mathrm{~mL} / \mathrm{min}$.

2.3. Quantification of $A F G_{1}$ before Treatment. To determine the apparent recovery (AR) for $\mathrm{AFG}_{1}$, concentrations of $\mathrm{AFG}_{1}\left(0.25\right.$ and $1 \mu \mathrm{L}$ of the $\mathrm{AFG}_{1}$ reference standard) were spiked to a blank within a calibration range of $156.25-5000 \mu \mathrm{g} / \mathrm{kg}$. The limit of detection (LOD) and limit of quantification (LOQ) were also determined. The mycotoxin $\left(\mathrm{AFG}_{1}\right)$ in millet was analysed by liquid chromatographytandem mass spectrometry (LC-MS/MS), described by Sulyok et al. [19]. The extraction of $\mathrm{AFG}_{1}$ was performed in a $50 \mathrm{~mL}$ polypropylene tube (Sarstedt, Nümbrecht, Germany) by homogenising $5 \mathrm{~g}$ of the pulverised millet sample with an extraction solvent $(20 \mathrm{~mL})$ containing acetonitrile/water/ formic acid $(79: 20: 1, \mathrm{v} / \mathrm{v} / \mathrm{v})$ for $90 \mathrm{~min}$ on a GFL 3017 rotary shaker (GFL, Burgwedel, Germany). The filtrate $(500 \mu \mathrm{L})$ was then injected into the LC-MS/MS system to determine the level of $\mathrm{AFG}_{1}$.

2.4. Decontamination of $A F G_{1}$ in Millet. The millet samples were treated with the nanoformulations (Mont, Mont-Na, Mont-LGEO, and Mont-LGP) at $8 \%$ and $12 \%$ concentrations in duplicates and put in storage for 4 weeks at a temperature of $30^{\circ} \mathrm{C}$ in the incubator according to the modified method of Atanda and Olopade [12]. The control (untreated millet sample) from the initial batch was also stored at $30^{\circ} \mathrm{C}$ just as the treated millet samples. Quantification of the levels of $\mathrm{AFG}_{1}$ in the treated millet samples was carried out weekly for up to four weeks according to the LCMS/MS method of Sulyok et al. [19].

2.5. Data Analysis. IBM SPSS statistics software (ver. 23, 2015 Inc., Chicago, IL, USA) was used to perform a normality test on the results obtained, after which the nonparametric test was performed to compare the median of the various nanoformulations analysed in duplicates within 4 weeks to check for significance at $p<0.05$ since the data was not a normal distribution. Thermogravimetric analysis curves were generated by using the Origin software (version 8.5, OriginLab Corporation Northampton, MA, USA) to plot the weight loss in the nanoformulations against the temperature of the nanoformulations when heated. 


\section{Results and Discussion}

3.1. Thermogravimetric Analysis (TGA) of the Nanoformulations from Montmorillonite Clay and Lemongrass Extracts. Thermogravimetric analysis curves of montmorillonite powder, montmorillonite- $\mathrm{Na}$, montmorillonitelemongrass essential oil, and montmorillonite-lemongrass powder are shown in Figures 1-4, respectively. The thermogravimetric analysis of the various nanoformulations in this study is very crucial to determine how stable and potent the nanoformulations used for the decontamination of mycotoxins will be over time. The first degradation for montmorillonite $\mathrm{K} 10$ was observed at $100.94^{\circ} \mathrm{C}$. The second degradation for Mont. was observed at $345.90^{\circ} \mathrm{C}$, while the third degradation occurred at $641.89^{\circ} \mathrm{C}$ (Figure 1). For Mont-Na, the first degradation occurred at $81.71^{\circ} \mathrm{C}$, while the second one occurred at $344.02^{\circ} \mathrm{C}$, and the third degradation at $643.77^{\circ} \mathrm{C}$, as shown in Figure 2. The montmorillonite clay contains water due to lattice water outside the coordination sphere of the spinel clay layers [20]. Therefore, the first degradation for the nanoformulations Mont and Mont-Na occurred at about the same temperature, which was as a result of a loss in the water of hydration in the formulations. The percentage loss in the first and second degradation for Mont. was 6 and 5\%, respectively. For Mont-Na, 8.5\% weight loss was recorded in the first degradation, while $6.5 \%$ weight loss was recorded in the second degradation. There were similarities in the degradation patterns of Mont. and Mont$\mathrm{Na}$. The visible change was the loss of water of hydration which occurred from $100^{\circ} \mathrm{C}$ in unmodified montmorillonite clay to $87.17^{\circ} \mathrm{C}$ in Mont-Na.

The first, second, and third degradations for MontLGEO occurred at $279.73,398.42$, and $667.55^{\circ} \mathrm{C}$, respectively with a weight loss of $3.5,10.0$, and $2.5 \%$ (Figure 3 ). For Mont-LGP, the first degradation occurred at $258.88^{\circ} \mathrm{C}$, whereas the second degradation occurred twice at $379.58^{\circ} \mathrm{C}$ and the third at $640.21^{\circ} \mathrm{C}$ (Figure 4). The weight loss in the first, second, and third degradation for Mont-LGP was 4.5, 18.5 , and $8 \%$, respectively. The initial loss of water of hydration in unmodified montmorillonite clay occurred at $100^{\circ} \mathrm{C}$. However, the presence of lemongrass in the compositions slowed down the loss of water of hydration within the nanoformulations. Also, montmorillonite comprises tetrahedral silica and octahedral alumina layers, which possess negative charges that can be balanced by exchangeable cations within its interlayers [21].

The combined thermogravimetric (TGA) curve in Figure 5 confirmed that the degradation of Mont. and Mont-Na were very similar and occurred at a steady rate. The curve for Mont-LGEO showed that degradation occurred at a slow pace compared with Mont-LGP. The TGA curve for MontLGEO showed a gradual degradation, whereas the TGA curve for Mont-LGP showed a fast and sharp irregular degradation pattern. The results indicate that the presence of the admixtures of lemongrass essential oil increases the thermal stability of the nanoformulation. The silicate layers distributed evenly in the montmorillonite sheet exhibited intermolecular interaction with the radical products from the nanoformulations of lemongrass essential oil, which

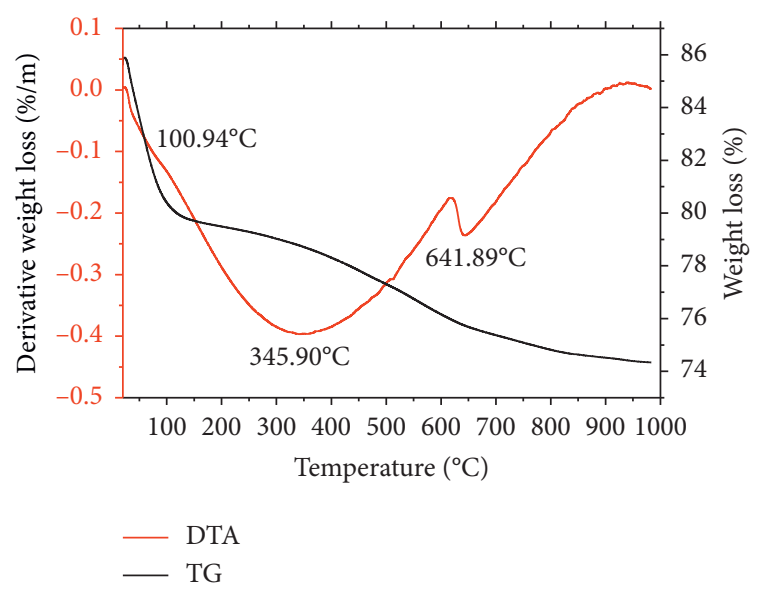

Figure 1: TGA/DTA curves showing the degradation pattern of montmorillonite clay.

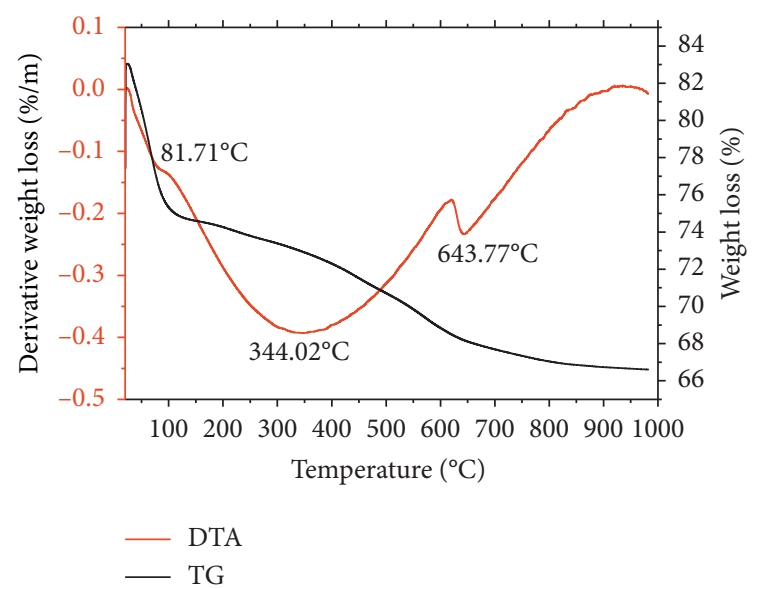

FIgURE 2: TGA/DTA curves showing the degradation pattern of montmorillonite-Na.

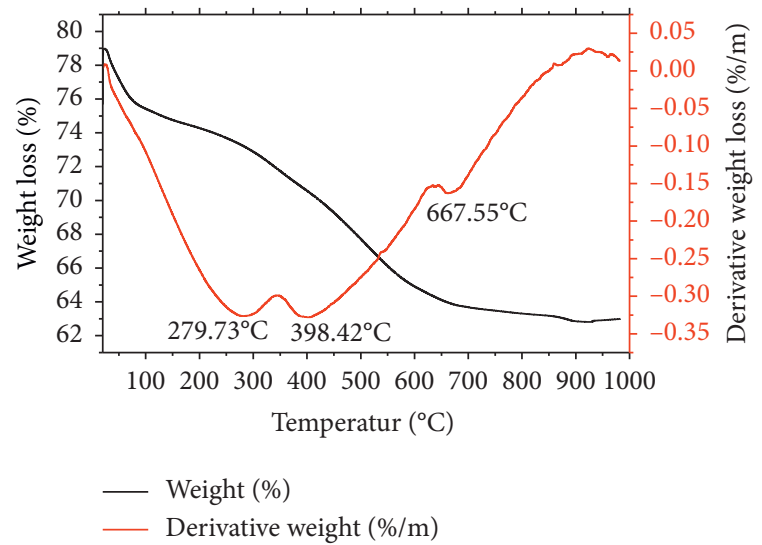

FIgURE 3: TGA/DTA curves showing the degradation pattern of montmorillonite-lemongrass essential oil.

consists mostly of geranial derivatives. Hence, Mont-LGEO will be more stable and potent compared with Mont-LGP. Generally, mycotoxin removal from foods by 


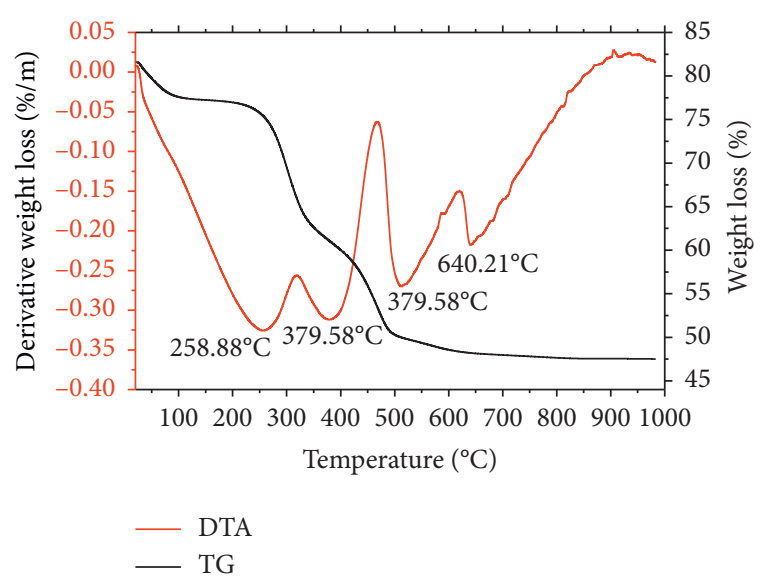

FIgURE 4: TGA/DTA curves showing the degradation pattern of montmorillonite-lemongrass powder.

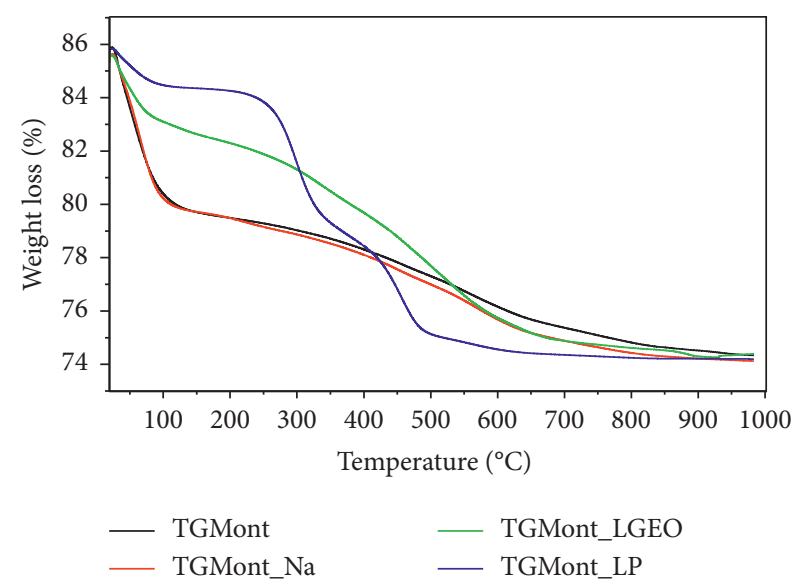

FIGURE 5: Combined TGA curves showing the degradation patterns of Mont, Mont-Na, Mont-LGEO, and Mont-LGP.

montmorillonite clay occurs through the mechanism of adsorption $[16,22]$. The adsorption process was improved by the exchange of cations between the lemongrass extract and the montmorillonite clay. However, adsorption is a reversible process under unstable conditions $[23,24]$. Hence, the TGA of the nanoformulations was performed to determine the most stable nanoformulation that will not be prone to degradation, thereby compromising the mycotoxin decontamination process.

The apparent recovery for $\mathrm{AFG}_{1}$ was $100 \%$, while its limit of detection (LOD) and limit of quantification (LOQ) were 0.002 and $0.006 \mu \mathrm{g} / \mathrm{kg}$, respectively. Figures 6 and 7 show the level of decontamination of $\mathrm{AFG}_{1}$ in the millet sample after treatment with $8 \%$ and $12 \%$ of the nanoformulations for 4 weeks. More decontamination of $\mathrm{AFG}_{1}$ was observed after the third week. However, the normality test carried out showed that the data were not normally distributed. Therefore, the Kruskal-Wallis nonparametric test was applied. The nonparametric test showed that there was no significant difference in the median of the various nanoformulations within the first to fourth week of treatment at $p<0.05$. The control measuring $0.001 \mu \mathrm{g} / \mathrm{kg}$ was constant

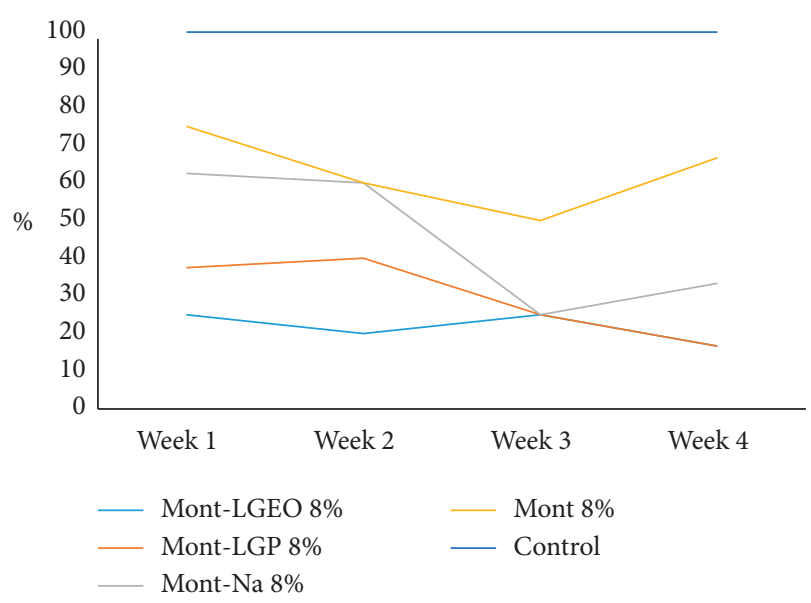

Figure 6: Percentage reduction of $\mathrm{AFG}_{1}$ after $8 \%$ of each treatment for 4 weeks.

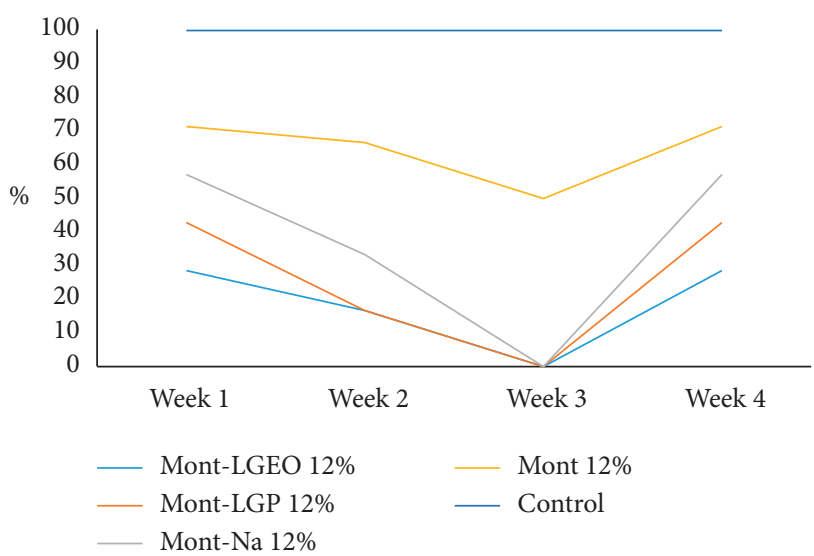

FIgURE 7: Percentage reduction of $\mathrm{AFG}_{1}$ after $12 \%$ of each treatment for 4 weeks.

throughout the four weeks. The nanoformulations did not show any significant difference in the decontamination of $\mathrm{AFG}_{1}$ in the millet samples compared with the control. However, in the previous studies, Mont-Na was proven to be the most efficient in decontaminating $\mathrm{T}-2$ toxin in maize [14], while Mont-LGP was the most efficient in decontaminating zearalenone in millet [15]. Other studies have also shown that bentonite which is mainly montmorillonite is effective in the adsorption of mycotoxins, particularly aflatoxins $[25,26]$.

\section{Conclusion}

This study showed that nanoformulations of montmorillonite clay with C. citratus are quite relatively resistant to degradation with the combination of montmorillonite and lemongrass essential oil more resistant than sodium-exchanged montmorillonite and montmorillonite modified with lemongrass powder. Therefore, nanoformulations from montmorillonite clay and lemongrass essential oil can serve as stable mycotoxin-decontaminating agents in stored cereal grains. 


\section{Data Availability}

The data used to support the findings of this study are available from the corresponding author upon request.

\section{Conflicts of Interest}

The authors declare that there are no conflicts of interest regarding the publication of this paper.

\section{Acknowledgments}

The authors are grateful to Covenant University and the University of Johannesburg for their sponsorship towards the publication of this paper.

\section{References}

[1] M. C. Di Gregorio, D. V. D. Neeff, A. V. Jager et al., "Mineral adsorbents for prevention of mycotoxins in animal feeds," Toxin Reviews, vol. 33, no. 3, pp. 125-135, 2014.

[2] M. Massaro, C. G. Colletti, G. Lazzara, and S. Riela, "The use of some clay minerals as natural resources for drug carrier applications," Journal of Functional Biomaterials, vol. 9, no. 1, p. $58,2018$.

[3] F. Bergaya and G. Lagaly, "Developments in clay science," in General Introduction: Clays, Clay Minerals, and Clay Science, pp. 1-18, Elsevier, Oxford, UK, 2006.

[4] C. Aguzzi, P. Cerezo, C. Viseras, and C. Caramella, "Use of clays as drug delivery systems: possibilities and limitations," Applied Clay Science, vol. 36, no. 1-3, pp. 22-36, 2007.

[5] E. Owaga, R. Muga, H. Mumbo, and F. Aila, "Chronic dietary aflatoxins exposure in Kenya and emerging public health concerns of impaired growth and immune suppression in children," International Journal of Biological and Chemical Sciences, vol. 5, no. 3, pp. 1325-1336, 2011.

[6] M. E. Kimanya, C. P. Shirima, H. Magoha et al., "Co-exposures of aflatoxins with deoxynivalenol and fumonisins from maize based complementary foods in Rombo, Northern Tanzania," Food Control, vol. 41, pp. 76-81, 2014.

[7] M. C. Adetuniji, O. O. Atanda, C. N. Ezekiel et al., "Distribution of mycotoxins and risk assessment of maize consumers in five agro-ecological zones of Nigeria," European Food Research and Technology, vol. 239, no. 2, pp. 287-296, 2014.

[8] M. S. Oliveira, A. Rocha, M. Sulyok, R. Krska, and C. A. Mallmann, "Natural mycotoxin contamination of maize (Zea mays L.) in the South region of Brazil," Food Control, vol. 73, pp. 127-132, 2017.

[9] N. Hojnik, U. Cvelbar, G. Tav̌car-Kalcher, J. L. Walsh, and I. Krizaj, "Mycotoxin decontamination of food: cold atmospheric pressure plasma versus "classic" decontamination," Toxins, vol. 9, no. 1, pp. 151-169, 2017.

[10] H. Nazarizadeh and J. Pourreza, "Evaluation of three mycotoxin binders to prevent the adverse effects of aflatoxin $B_{1}$ in growing broilers," Journal of Applied Animal Research, vol. 47, no. 1, pp. 135-139, 2019.

[11] S. A. Bankole and A. O. Joda, "Effect of lemon grass (Cymbopogon citratus) powder and essential oil on mould deterioration and aflatoxin contamination of melon seeds (Colocynthis citrullus L.)," African Journal of Biotechnology, vol. 3, no. 1, pp. 52-59, 2004, http://www.academicjournal. org/AJB.
[12] O. O. Atanda and T. A. Olopade, "Effect of lemon grass (Cymbopogon citratus (DC) Stapf.) treatment on Aspergillus flavus (SGS-421) infestation and aflatoxin $B_{1}$ content of maize grains," International Food Research Journal, vol. 20, no. 4, pp. 1933-1939, 2013.

[13] A. Perczak, K. Jus, K. Marchwińska et al., "Degradation of zearalenone by essential oils under in vitro Conditions," Frontiers in Microbiology, vol. 7, no. 1, p. 1224, 2016.

[14] B. K. Olopade, S. U. Oranusi, O. C. Nwinyi et al., "Modification of montmorillonite clay with Cymbopogon citratus for the decontamination of zearalenone in millet," AIMS Agriculture and Food, vol. 4, no. 3, pp. 643-657, 2019.

[15] B. K. Olopade, S. U. Oranusi, O. C. Nwinyi et al., "Decontamination of T-2 toxin in maize by modified montmorillonite clay," Toxins, vol. 11, no. 1, p. 616, 2019.

[16] A. M. Alvarado, R. Zamora-Sanabria, and F. GranadosChinchilla, "A focus on aflatoxins in feedstuffs: levels of contamination, prevalence, control strategies, and impacts on animal health," in Aflatoxin-Control, Analysis, Detection and Health Risks, L. M. Abdulra'uf, Ed., pp. 116-152, IntechOpen, London, UK, 2017.

[17] M. E. Ojewumi, M. G. Banjo, M. O. Oresegun et al., "Analytical investigation of the extract of lemongrass leaves in repelling mosquito," International Journal of Pharmaceutical Sciences and Research, vol. 8, no. 5, pp. 2048-2055, 2017.

[18] J. A. Noudem, M. G. Nguemtchouin Mbouga, K. G. Kaptso, M. Khalfaoui, and G. B. Noumi, "Saponins-clay modified materials: a new approach against Callosobruchus subinnotatus in stored products," International Journal of Scientific and Technology Research, vol. 6, no. 6, pp. 134-141, 2017.

[19] M. Sulyok, F. Berthiller, R. Krska, and R. Schuhmacher, "Development and validation of a liquid chromatography/ tandem mass spectrometric method for the determination of 39 mycotoxins in wheat and maize," Rapid Communications in Mass Spectrometry, vol. 20, no. 18, pp. 2649-2659, 2006.

[20] J. A. Adekoya, M. D. Khan, and N. Revaprasadu, "Phase transition in $\mathrm{Cu} 2+\mathrm{xSnS} 3+\mathrm{y}(0 \leq \mathrm{x} \leq 2 ; 0 \leq \mathrm{y} \leq 1)$ ternary systems synthesized from complexes of coumarin derived thiocarbamate motifs: optical and morphological properties," RSC Advances, vol. 9, no. 61, pp. 35706-35716, 2019.

[21] Y. Xi, W. Martens, H. He, and R. L. Frost, "Thermogravimetric analysis of organoclays intercalated with the surfactant octadecyltrimethylammonium bromide," Journal of Thermal Analysis and Calorimetry, vol. 81, no. 1, pp. 91-97, 2005.

[22] S. L. Lemke, P. G. Grant, and T. D. Phillips, "Adsorption of zearalenone by organophilic montmorillonite clay," Journal of Agricultural and Food Chemistry, vol. 46, no. 9, pp. 37873796, 1998.

[23] S. J. Zarrouk and K. Mclean, "Advanced analytical pressuretransient analysis relevant to geothermal wells," Geothermal Well Test Analysis, p. 89, 2019.

[24] A. A. Adeyemo, I. O. Adeoye, and O. S. Bello, "Adsorption of dyes using different types of clay: a review," Applied Water Science, vol. 7, no. 2, pp. 543-568, 2017.

[25] C. Kong, S. Shin, and B. Kim, "Evaluation of mycotoxin sequestering agents for aflatoxin and deoxynivalenol: an in vitro approach," SpringerPlus, vol. 3, no. 1, pp. 346-351, 2014.

[26] P. Vila-Donat, S. Marín, V. Sanchis, and A. J. Ramos, "In vitro assessment of new efficient mycotoxin adsorbents based on bentonites," in Proceedings of the Personal Communication B. 31st EFFOST International Conference, pp. 2-196, Sitges, Spain, November 2017. 